\title{
ANÁLISE DA INFLUÊNCIA DAS ATIVIDADES ANTRÓPICAS SOBRE A QUALIDADE DA ÁGUA DA APA ITUPARARANGA (SP), BRASIL
}

\author{
Vanessa Cezar Simonetti ${ }^{1}$ \\ Darllan Collins da Cunha e Silva² \\ André Henrique Rosa ${ }^{3}$
}

Resumo: A problemática relacionada aos recursos hídricos tem sido palco de debates devido a constante deterioração da qualidade da água e aumento de sua demanda. Assim, este estudo objetivou analisar a influência do uso e ocupação da terra na qualidade da água dos principais cursos de água da Área de Proteção Ambiental (APA) Itupararanga (SP). Para tanto, foram realizadas análises dos principais parâmetros e índices de qualidade das águas, bem como o mapeamento do uso e ocupação da terra. Os resultados revelaram que as condições de esgotamento sanitário dos municípios da APA Itupararanga e as classes de usos agrícolas estão impactando negativamente na qualidade da água.

Palavras-chave: Bacia hidrográfica. Geoprocessamento. Índices. Multivariada. Áreas Protegidas.

\section{ANALYSIS OF THE INFLUENCE OF ANTHROPIC ACTIVITIES ON THE WATER QUALITY OF EPA ITUPARARANGA (SP), BRAZIL}

Abstract: The problems related to water resources has been the scene of debates due to steady deterioration of water quality and increase in demand. This study aimed to analyse the influence of land use and occupation in the water quality of the main rivers of the Environmental Protection Area (EPA) Itupararanga (SP), Brazil. Therefore, analyses were carried out of the main parameters and water quality indices, as well as the mapping of the use and occupation of land. The results revealed that the sanitary sewage conditions of the municipalities of the EPA Itupararanga and agricultural uses classes are negatively affecting the water quality.

Keywords: Watershed. Geoprocessing. Index. Multivariate. Protected Area.

\section{ANÁLISIS DE LA INFLUENCIA DE LAS ACTIVIDADES ANTRÓPICAS SOBRE LA CALIDAD DEL AGUA DE APA ITUPARARANGA (SP), BRASIL}

Resumen: La problemática relacionada con los recursos hídricos ha sido escenario de debates debido al constante deterioro de la calidad del agua y aumento de su demanda. Así, este estudio objetivó analizar la influencia del uso y ocupación de la tierra en la calidad del agua de los principales cursos de agua del Área de Protección Ambiental (APA) Itupararanga (SP). Para ello, se realizaron análisis de los principales parámetros e índices de calidad de las aguas, así como el mapeo del uso y ocupación de la tierra. Los resultados revelaron que las condiciones de agotamiento sanitario de los municipios de la APA Itupararanga y las clases de usos agrícolas están impactando negativamente en la calidad del agua.

\footnotetext{
1 Universidade Estadual Paulista "Júlio de Mesquita Filho" - Unesp, Campus de Sorocaba, Sorocaba - SP, Brasil, va simonetti@hotmail.com, https://orcid.org/0000-0001-6845-4875

2 Universidade Estadual Paulista "Júlio de Mesquita Filho" - Unesp, Campus de Registro, Registro - SP, Brasil, darllanamb@yahoo.com.br, https://orcid.org/0000-0003-3280-0478

3 Universidade Estadual Paulista "Júlio de Mesquita Filho" - Unesp, Campus de Sorocaba, Sorocaba - SP, Brasil, ahrosa@sorocaba.unesp.br, https://orcid.org/0000-0002-2042-018X
} 
Palabras clave: Cuenca hidrográfica. Geoprocesamiento. Índices. Multivariante. Áreas Protegidas.

\section{Introdução}

O constante aumento populacional demanda cada vez mais a oferta de água e, diante deste panorama, os recursos hídricos encontram-se cada vez mais fragilizados. Embora haja um consenso comum sobre a importância da água como um bem fundamental, têm se observado ao longo das décadas uma constante degradação de sua qualidade, fato que impacta diretamente na sua disponibilidade.

Isso ocorre por diversos fatores, dentre os quais, os mais relevantes concernem a má gestão governamental, que reflete na precariedade do sistema de esgotamento sanitário nos centros urbanos, e na falha dos processos de fiscalização dos despejos industriais (PIROLI, 2016). Ainda, o desmatamento das matas ciliares e redução das áreas florestais, bem como à compactação do solo rural e urbano e a impermeabilização do solo reduzem a infiltração da água no solo e, consequentemente, causa o rebaixamento do nível freático.

O atual modelo de uso e ocupação da terra traz diversas implicações, uma vez que os processos relacionados à ocupação da terra são bastante acentuados e ocorrem de forma desordenada e intensa nas grandes e médias cidades (PEREIRA; BISSANI, 2017). O crescimento populacional exacerbado das cidades tem impossibilitado a resiliência dos ecossistemas naturais presentes no ambiente urbano (COELHO et al., 2018; SILVA et al., 2018).

Não obstante, as áreas rurais também são responsáveis por severas alterações no uso da terra, amplificando os impactos negativos nos recursos hídricos, uma vez que o uso indiscriminado de defensivos agrícolas e fertilizantes são carreados para os corpos de água. Ainda, é importante salientar que não é incomum as propriedades rurais não atenderem ao cumprimento das reservas legais e áreas de APP previstas no Novo Código Florestal (Lei Federal no 12.651/2012).

Contrastando com esse cenário, tem aumentado o uso de recursos tecnológicos que auxiliam na análise e monitoramento ambiental, tais como Sistemas de Informações Geográficas (SIG) e Sensoriamento Remoto (SR), propiciando a integração de dados remotos com dados obtidos in situ, aumentando a eficiência do monitoramento e avaliação ambiental no que concerne a escala temporal e espacial (SILVA et al., 2017a; SILVA et al., 2018).

As ferramentas geoespaciais são amplamente empregadas no monitoramento de reservatórios e Áreas Protegidas. Nesse sentido, o reservatório de Itupararanga, inserido na Área de Proteção Ambiental (APA) Itupararanga (SP) foi palco de 
diversos estudos que incluíram a sua biodiversidade e os impactos do uso e ocupação da terra no seu entorno, bem como as implicações nos organismos aquáticos (SALLES et al., 2008; TANIWAKI et al., 2013; BEGHELLI et al., 2014; PEDRAZZI et al., 2014; CONCEIÇÃO et al., 2015; FRASCARELI et al., 2015).

Diante do exposto, e tendo em vista a necessidade da avaliação constante dos recursos naturais à luz de sua preservação, o presente trabalho tem como objetivo analisar a influência do uso e ocupação da terra na qualidade da água dos principais cursos de água da APA Itupararanga.

\section{Material e Métodos}

\section{Localização e caracterização da área de estudo}

A área de estudo compreende a Área de Proteção Ambiental (APA) Itupararanga, pertencente a Unidade de Gerenciamento de Recursos Hídricos do Sorocaba e Médio Tietê (UGRHI 10 - SMT), composta pelos afluentes da sub-bacia do Alto Sorocaba, sendo os rios Una, Sorocabuçu e Sorocamirim os principais afluentes formadores do reservatório de Itupararanga e rio Sorocaba (Figura 1).

Figura 1. Localização da APA Itupararanga e pontos amostrados

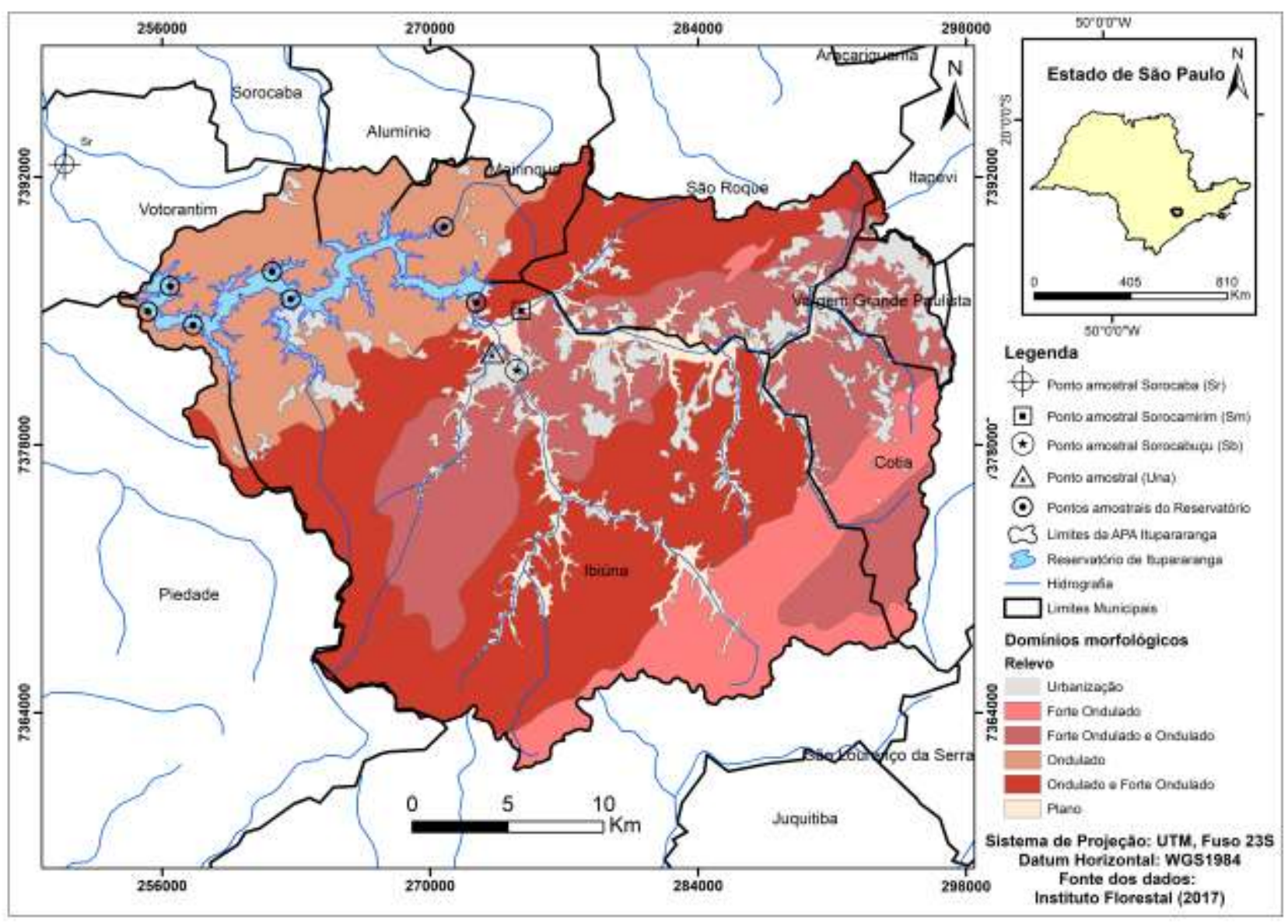


Fonte: Elaborado pelos autores, 2019

A APA foi instituída pela Lei Estadual ㄲo 10.100/1998, com vistas a assegurar a manutenção da qualidade da água da represa, bem como à diversidade biológica e o ordenamento do uso e ocupação da terra. Posteriormente, às áreas de cabeceira foram incorporadas à APA e regulamentadas pela Lei Estadual oㅜ 11.579/2003. A área da APA abrange cerca de oito municípios, sendo Votorantim, Alumínio, Mairinque, Ibiúna, São Roque, Piedade, Vargem Grande Paulista e Cotia (BEU; MISATO; HAHN, 2011).

O clima da região é de verão chuvoso e inverno com estiagem, apresentando uma pluviosidade média anual de $1.492 \mathrm{~mm}$, no qual janeiro representa o mês com maior precipitação, sendo $248 \mathrm{~mm}$ e agosto o mês mais seco, com $43 \mathrm{~mm}$. A vegetação é composta pelos domínios de Floresta Ombrófila Densa (SÃO PAULO, 2010).

Quanto aos aspectos geomorfológicos, a bacia hidrográfica está situada nos limites do Planalto Atlântico e Depressão Periférica, com classes representadas por Escarpas Festonadas Mares de Morros, Mesas Basálticas Morros com Serras Restritas, Morros Paralelos, Morros de Topos Achatados e Planícies Aluviais. Os aspectos litológicos são constituídos por dois domínios principais, sendo o São Roque, representado por metassedimentos e metabásicas, e Embu, representado pelos gnaisses e apresentando diversas outras associações. Os aspectos litológicos são representados por três classes principais, sendo Argissolo, Cambissolo e Latossolo (SÃO PAULO, 2010).

\section{Amostragem e métodos analíticos utilizados}

Foram amostrados os principais afluentes da cabeceira do reservatório, tais como o rio Una (Una), rio Sorocabuçu (Sb) e rio Sorocamirim (Sm), bem como sete pontos amostrais no reservatório de Itupararanga (RI). Também foi analisado um ponto amostral a jusante do reservatório, no rio Sorocaba ( $\mathrm{Sb}$ ), de modo a obter uma visão geral da qualidade da água.

O estudo foi conduzido em dois períodos distintos, sendo a primeira campanha realizada no período chuvoso (dezembro de 2016), e a segunda campanha no período seco (agosto de 2017), deste modo, foi possível a avaliação sazonal da qualidade da água na área de estudo. No reservatório a coleta foi realizada com auxílio de barco nos sete pontos, e para os demais cursos d'água, a coleta foi realizada com auxílio de corda e balde plástico, e armazenada em garrafas 
novas de polietileno de alta resistência, nas profundidades de 20 a $30 \mathrm{~cm}$ da lâmina d'água.Todas as etapas da coleta e preservação das amostras seguiram os critérios estabelecidos pelo Standard Methods for the Examination of Water and Wastewater (APHA, 1999).

Foram determinadas in situ as variáveis físico-químicas por meio de uma sonda multiparâmetros da marca HORIBA Water Checker U-40, sendo potencial hidrogeniônico $(\mathrm{pH})$, temperatura (Temp - $\left.{ }^{\circ} \mathrm{C}\right)$, condutividade elétrica (Cond $-\mu \mathrm{S} \mathrm{cm}^{-}$ $\left.{ }^{1}\right)$, oxigênio dissolvido (OD - $\left.m g \mathrm{~L}^{-1}\right)$, potencial redox $\left(\mathrm{PR}-\mathrm{m} \mathrm{V}^{-1}\right)$ e turbidez (Turb NTU). As análises off-site foram realizadas no Laboratório de Química e Microbiologia da Unesp-ICTS, tais como nitrogênio total (NT - $\mathrm{mg} \mathrm{L}^{-1}$ ) e fósforo total (FT - mg L-1) com leitura em espectrofotômetro de UV-Visível HACH-DR 2800, de acordo com a metodologia 10071 e 8190. A clorofila-a foi obtida pelo método de Wetzel e Likens (2000), sendo utilizada acetona $90 \%$ como solvente no processo de extração dos pigmentos fotossintéticos.

As análises de demanda bioquímica de oxigênio (DBO) foram realizadas por meio da diferença entre o oxigênio inicial e após cinco dias de incubação a $20 \stackrel{\circ}{\circ}$ $\left(\mathrm{DBO}_{5,20}\right)$. O resíduo total ( $\mathrm{RT}$ - $\mathrm{mg} \mathrm{L}^{-1}$ ) foi estimado de acordo com a diferença entre o peso da secagem em béquer de uma alíquota de $100 \mathrm{~mL}$ de água bruta previamente pesada à $105^{\circ} \mathrm{C}$ na estufa de aeração. Foram enviadas amostras a um laboratório certificado de Sorocaba para realização das análises de coliformes totais (NMP $100 \mathrm{~mL}^{-1}$ ) e fecais (NMP $100 \mathrm{~mL}^{-1}$ ).

\section{Índices de qualidade das águas contemplados no estudo}

Para melhor inferir sobre a qualidade da água dos principais cursos de água da APA Itupararanga, foi empregado o Índice de Qualidade das Águas (IQA) e Índice de Estado Trófico (IET) (CETESB, 2017), que consiste em um índice amplamente utilizado no monitoramento da qualidade da água no estado de São Paulo, sendo utilizado em estudos que visam a análise e monitoramento da qualidade da água (FRASCARELI et al., 2015; MENEZES et al., 2016; ROSA et al., 2015). Possui uma escala de 0 a 100, que infere sobre o nível de contaminação presente no corpo de água por meio da avaliação integrada de nove parâmetros de qualidade da água considerados relevantes para fins de abastecimento público, cujos pesos foram: OD $(0,17)$; CF $(0,15) ; \mathrm{pH}(0,12)$; DBO $(0,10)$; NT $(0,10)$; FT $(0,10)$; Temp $(0,10)$; Turb $(0,08)$; RT $(0,08)$ e T $\left({ }^{\circ} \mathrm{C}\right), 0,10$.

Foi calculado o Índice de Estado Trófico (IET) modificado por Lamparelli (2004) para ambientes tropicais e subtropicais, com a utilização das variáveis FT e 
Cl-a, sendo empregadas as fórmulas para ambientes lênticos: IET $(F T)=10 \times(6$ $(1,77-0,42 x(\ln \mathrm{PT}) / \mathrm{In} 2))$; IET (Cl-a) = 10x(6-((0,92-0,34x(In Cl-a))/In 2)). Para os ambientes lóticos foram utilizadas as fórmulas: IET $(\mathrm{Cl}-\mathrm{a})=10 \times(6-((-0,7-0,6 \times(\mathrm{In}$ $\mathrm{CL})) /$ In 2))-20 e IET (FT)=10x(6-((0,42-0,36x(In PT))/In 2))-20 (CETESB, 2017).

O Indicador de Coleta e Tratabilidade de Esgoto da População Urbana de Município (ICTEM), publicado pela CETESB (2017), foi utilizado para avaliar as condições sanitárias dos municípios inseridos na APA Itupararanga. O indicador contempla cinco variáveis, sendo a coleta; tratamento e eficiência de remoção; eficiência global de remoção; destino adequado de lodos e resíduos de tratamento e efluente da estação. O recorte dos dados do ICTEM e a elaboração do mapa com os respectivos valores foi realizado por meio do software ArcGis 10.4.1.

\section{Análise espacial da Área de Proteção Ambiental (APA) Itupararanga}

Foi realizada a análise espacial da área de estudo a partir de técnicas de geoprocessamento associadas a sensoriamento remoto (SR) e sistema de informação geográfica (SIG) para mapeamento e retificação do uso da terra na APA Itupararanga.

O plano de informação referente ao uso e ocupação do solo da APA Itupararanga foi elaborado a partir da retificação dos mapas de Unidades Homogêneas de uso e ocupação do solo urbano (UHCT) e de Cobertura da Terra do Estado de São Paulo, disponibilizados pela Coordenadoria de Planejamento Ambiental do Estado de São Paulo (CPLA) na escala de 1:100.000 em dez novas classes de usos. Após, foi realizada a retificação das áreas agrícolas por meio da identificação visual de imagens orbitais (ano de 2017) por meio do software Google Earth, onde após serem identificadas e extraídas, foram exportadas para o software ArcGis 10.4.1 e sobrepostas ao mapa de uso da terra.

\section{Análise estatística multivariada}

Foi realizada a análise multivariada de componentes principais $(A C P)$, que possibilita a transformação de dados lineares em novos agrupamentos, permitindo a análise simultânea de uma série de conjunto de dados de um mesmo ou indivíduo, de modo que a primeira nova variável obtida resulte na maior variação de dados do conjunto, até que todas as variáveis contempladas no conjunto de dados sejam explicadas (HONGYU; SANDANIELO; OLIVEIRA JÚNIOR, 2015).

Para analisar a influência do uso e ocupação da terra e os possíveis agrupamentos com as variáveis de qualidade de água e índices avaliados no estudo 
foi realizada a análise Cluster pelo método Ward's Method com o quadrado da distância Euclidiana (TIMM, 2002).

Pelo fato de as variáveis analisadas no estudo possuírem diferentes escalas e unidades, foi realizada a normalização dos dados através da padronização da média total e desvio padrão de cada variável e período amostrado. A normalização é importante por possibilitar a retirada de qualquer influência e tornar os valores adimensionais (MENEZES et al., 2016). As análises foram realizadas no software PAST 3.0.

\section{Resultados e discussão}

\section{Uso e ocupação do solo da APA Itupararanga}

O reservatório de Itupararanga apresenta suma importância para a região; no entanto, seus usos múltiplos resultam em diversos conflitos (BEU; MISATO; HAHN, 2011). Partindo desta premissa, foi elaborado o mapa de uso e ocupação da terra da APA Itupararanga (Figura 2).

Figura 2. Análise do uso e ocupação da terra da APA Itupararanga, SP

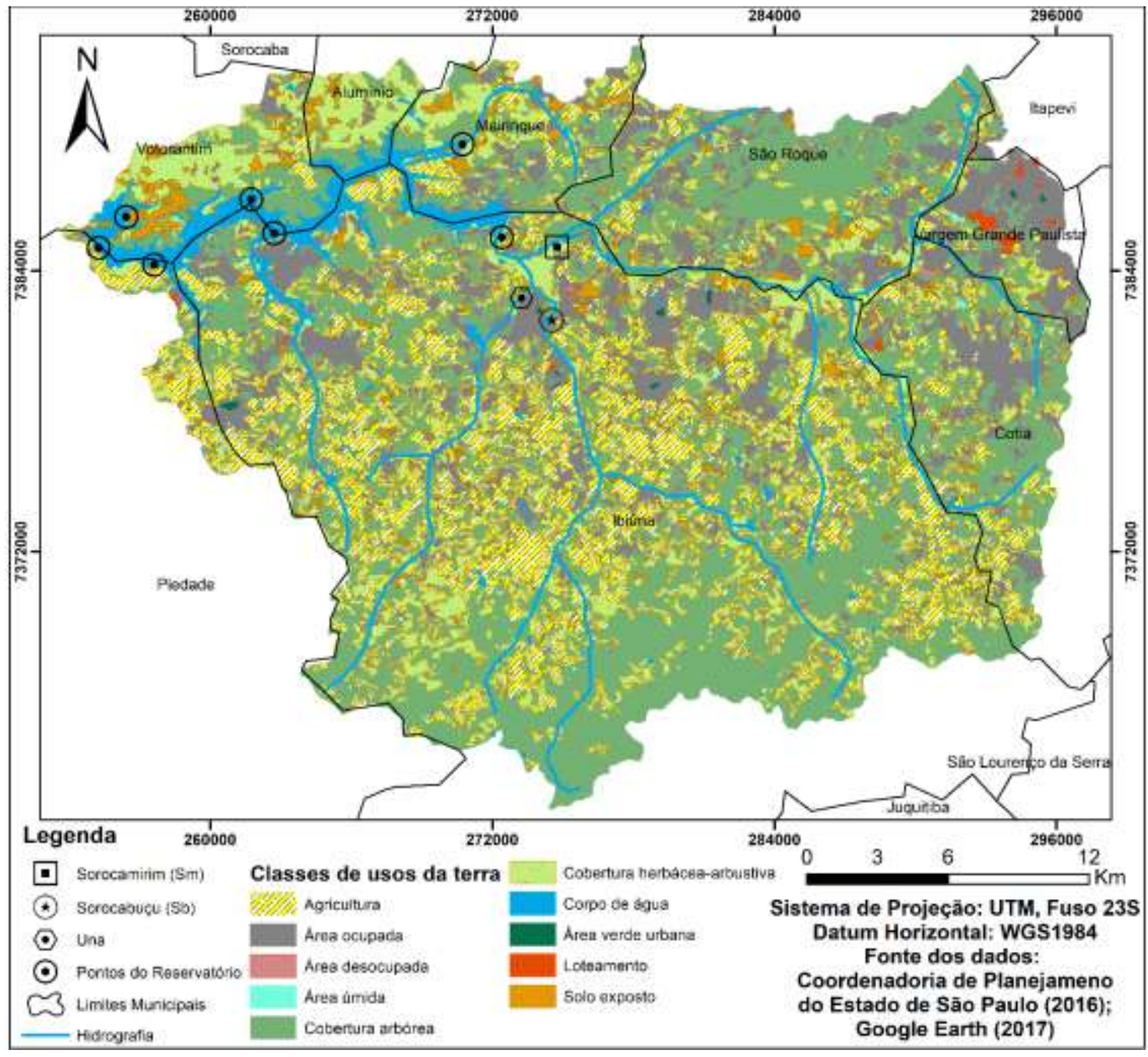


Fonte: Elaborado pelos autores, 2019

Com vistas a aumentar o nível de detalhamento do uso e ocupação da terra na APA Itupararanga, as classes de uso da terra foram analisadas individualmente de acordo com cada município inserido na APA (Tabela 1).

Tabela 1. Distribuição das classes de uso e ocupação da terra por municípios inseridos na APA Itupararanga

\begin{tabular}{|c|c|c|c|c|c|c|c|c|c|c|}
\hline \multirow[b]{2}{*}{ Municípios } & \multicolumn{10}{|c|}{ Classes de usos da terra (em km²) } \\
\hline & $\mathbf{A G}^{1}$ & $\mathrm{AOC}^{2}$ & $\mathrm{ADE}^{3}$ & $\mathbf{A U}^{4}$ & $\mathrm{CAR}^{5}$ & $\mathrm{CHA}^{6}$ & CAG $^{7}$ & AVU8 & LOT $^{9}$ & SOE $^{10}$ \\
\hline Alumínio & 0,03 & 0,67 & * & * & 4,47 & 9,18 & 1,81 & * & * & 1,11 \\
\hline Cotia & 7,29 & 23,24 & 0,16 & 0,22 & 38,02 & 11,31 & 0,11 & 0,03 & 0,14 & 1,05 \\
\hline Ibiúna & 99,16 & 94,18 & 0,16 & 0,34 & 258,04 & 109,94 & 10,53 & 0,49 & 0,06 & 10,14 \\
\hline Mairinque & 4,69 & 8,69 & * & 0,13 & 18,93 & 12,24 & 3,71 & * & * & 2,63 \\
\hline Piedade & 6,16 & 2,39 & * & 0,14 & 3,78 & 4,06 & 1,46 & * & 0,06 & 0,46 \\
\hline São Roque & 3,70 & 29,09 & * & 0,26 & 56,24 & 15,58 & 0,52 & * & * & 2,62 \\
\hline $\begin{array}{l}\text { Vargem } \\
\text { Grande } \\
\text { Paulista }\end{array}$ & 0,64 & 18,81 & 0,04 & 0,13 & 6,67 & 2,98 & * & 0,09 & 1,23 & 0,24 \\
\hline Votorantim & 1,06 & 2,48 & * & * & 13,57 & 14,67 & 9,56 & * & * & 4,43 \\
\hline
\end{tabular}

Legenda: (1) Agricultura; (2) Área Ocupada; (3) Area Desocupada; (4) Área Úmida; (5) Cobertura Arbórea; (6) Cobertura Herbácea-Arbustiva; (7) Corpo de água; (8) Área Verde Urbana; ${ }^{(9)}$ Loteamento; ${ }^{(10)}$ Solo Exposto.

Os resultados (Figura 2) demonstraram que as classes agrícolas estão distribuídas por toda a extensão da APA Itupararanga, com predominância no município de Ibiúna (Tabela 1), que apresentou uma área com produção agrícola de $99,16 \mathrm{~km}^{2}$, sendo um valor altamente expressivo em razão dos possíveis riscos associados ao aporte de fertilizantes e defensivos agrícolas aos recursos hídricos contidos na APA.

Ainda, o município apresentou uma área de 109,94 km² de cobertura herbácea-arbustiva composta por espécies forrageiras e pastagens. Nesse sentido, essas duas respectivas classes de usos contabilizam $35,87 \%$ dos usos da terra do município de lbiúna, enquanto os demais municípios, juntos, contabilizaram 23,57 $\mathrm{km}^{2}$ de classes agrícolas e $70,02 \mathrm{~km}^{2}$ de cobertura herbácea-arbustiva. Portanto, fica evidente a contribuição do município de Ibiúna com o potencial de aporte de substâncias aos recursos hídricos, principalmente ao que tange ao reservatório de Itupararanga, principal manancial de abastecimento público da região. 
De acordo com o Plano de Manejo (SÃO PAULO, 2010) que consiste no principal instrumento de gestão da APA Itupararanga, a atividade agrícola é composta predominantemente por pequenos produtores rurais, destacando os cultivos de olericulturas, como tomate, batata, morango, entre outras. Os impactos dessas atividades foram constatados nos estudos realizados por Conceição et al. (2015), que analisaram a composição química das águas pluviais dos afluentes da APA Itupararanga e constataram uma alta deposição de fosfatos e nitratos advindos de material particulado resultantes de atividades agrícolas. Nesse sentido, o presente estudo verificou grandes extensões de áreas agrícolas tanto nas subbacias de cabeceira quanto nas proximidades do reservatório de Itupararanga. Isso evidencia o potencial risco de poluição difusa que pode ocorrer na bacia hidrográfica do Alto Sorocaba, caso não sejam adotadas técnicas eficientes de manejo e conservação do solo nessas áreas.

As áreas ocupadas contemplam as áreas residenciais, comerciais, industriais e, também, as áreas pavimentadas (sistema viário), além das áreas edificadas, como chácaras residenciais e sítios distantes da zona urbana, sendo Ibiúna o município com a maior extensão inserida nessa classe, com $94,18 \mathrm{~km}^{2}$, seguido de São Roque $\left(29,09 \mathrm{~km}^{2}\right)$ e Cotia, com 23,24 km². O município de Vargem grande Paulista apresentou uma área de $18,81 \mathrm{~km}^{2}$; no entanto, essa classe apresenta uma representatividade de $61 \%$ das classes de uso do município, sendo um valor altamente significativo, sendo, portanto, o município com maior urbanização da APA Itupararanga.

De acordo com Poleto (2014), dentre as inúmeras interferências antrópicas presentes em uma bacia hidrográfica, os processos inerentes à urbanização resultam em significativas alterações em sua dinâmica hidrológica, aumentando a velocidade do escoamento superficial, uma vez que os usos antrópicos privilegiam a impermeabilização das áreas para construção civil, diminuindo a capacidade de infiltração da água no solo e recarga do lençol freático, podendo interferir no regime de chuvas da bacia hidrográfica. Nesse sentido, foi identificada uma extensão de $179,55 \mathrm{~km}^{2}$ de áreas impermeabilizadas inerentes aos processos de urbanização na APA Itupararanga.

As áreas com cobertura arbórea foram predominantes no município de lbiúna, com $258,04 \mathrm{~km}^{2}$, o que representou $44,26 \%$ das classes de uso do município, seguido por São Roque, com 56,24 km² e Cotia, com 38,02 km². Os municípios com menores áreas com cobertura arbórea foram Piedade $\left(3,78 \mathrm{~km}^{2}\right)$, Alumínio $(4,47$ $\mathrm{km}^{2}$ ) e Vargem Grande Paulista, com 6,67 km². Todavia, a cobertura arbórea 
mapeada no estudo não contemplou as diferentes tipologias florestais, o que implica na consideração de plantios de monoculturas, como Eucalyptus spp e Pinus (SÃO PAULO, 2010).

As classes de solo exposto foram predominantes no município de Ibiúna, com 10,14 km² em comparação aos demais municípios que, juntos, contabilizaram $12,54 \mathrm{~km}^{2}$. O solo exposto pode desencadear processos erosivos, carreando partículas de solos para os cursos de água (SIMONETTI et al., 2018; STEFANOSKI et al., 2013).

Considerando a importância da APA, diversos estudos foram realizados no sentido de analisar a influência do uso e ocupação do solo na qualidade da água do manancial. Taniwaki et al. (2013) estudaram os impactos na qualidade e genotoxicidade da água advindos dos diversos usos do seu entorno, sendo identificados altos níveis tróficos no reservatório, atribuídos, principalmente, pelas atividades agrícolas e ocupação urbana na bacia do Alto Sorocaba. Frascareli et al. (2015) identificaram uma heterogeneidade espacial e sazonal no reservatório de Itupararanga, atribuindo os elevados valores tróficos encontrados aos processos de ocupação e usos dos solos no entorno do reservatório. Estudos realizados por Rosa et al. (2015) também identificaram impactos na qualidade da água nos estudos realizados para avaliação da sustentabilidade da represa de Itupararanga, e encontraram poluições advindas dos diversos usos do entorno, tais como lançamento de efluentes das cidades próximas, além de deflúvios agrícolas e urbanos que aportam o reservatório, deteriorando a qualidade da água e comprometendo seriamente os organismos aquáticos.

A classe de uso da terra agrícola apresentou uma grande extensão e pulverização por toda APA, o que the confere um risco potencial de aporte de nutrientes provenientes das atividades agrícolas por meio de deflúvio pluvial que, segundo Silva et al. (2017b), pode arrastar sedimentos e material particulado para os corpos d'água, comprometendo a sua qualidade. Ainda, esse fato pode ser agravado se as áreas ripárias não apresentarem suas matas ciliares preservadas (OLIVEIRA et al., 2016).

De modo a complementar o estudo e analisar os municípios que impactam negativamente na qualidade ambiental da APA Itupararanga no tocante à poluição resultante da deficiência em saneamento básico, foi avaliado o Indicador de Coleta e Tratabilidade de Esgoto da População Urbana de Município - ICTEM, publicado pela CETESB em 2017, ano em que a análise de água foi realizada neste estudo (Figura 3). 
Figura 3. Análise do Indicador de Coleta e Tratabilidade de Esgoto da População Urbana de Município inseridos na APA Itupararanga

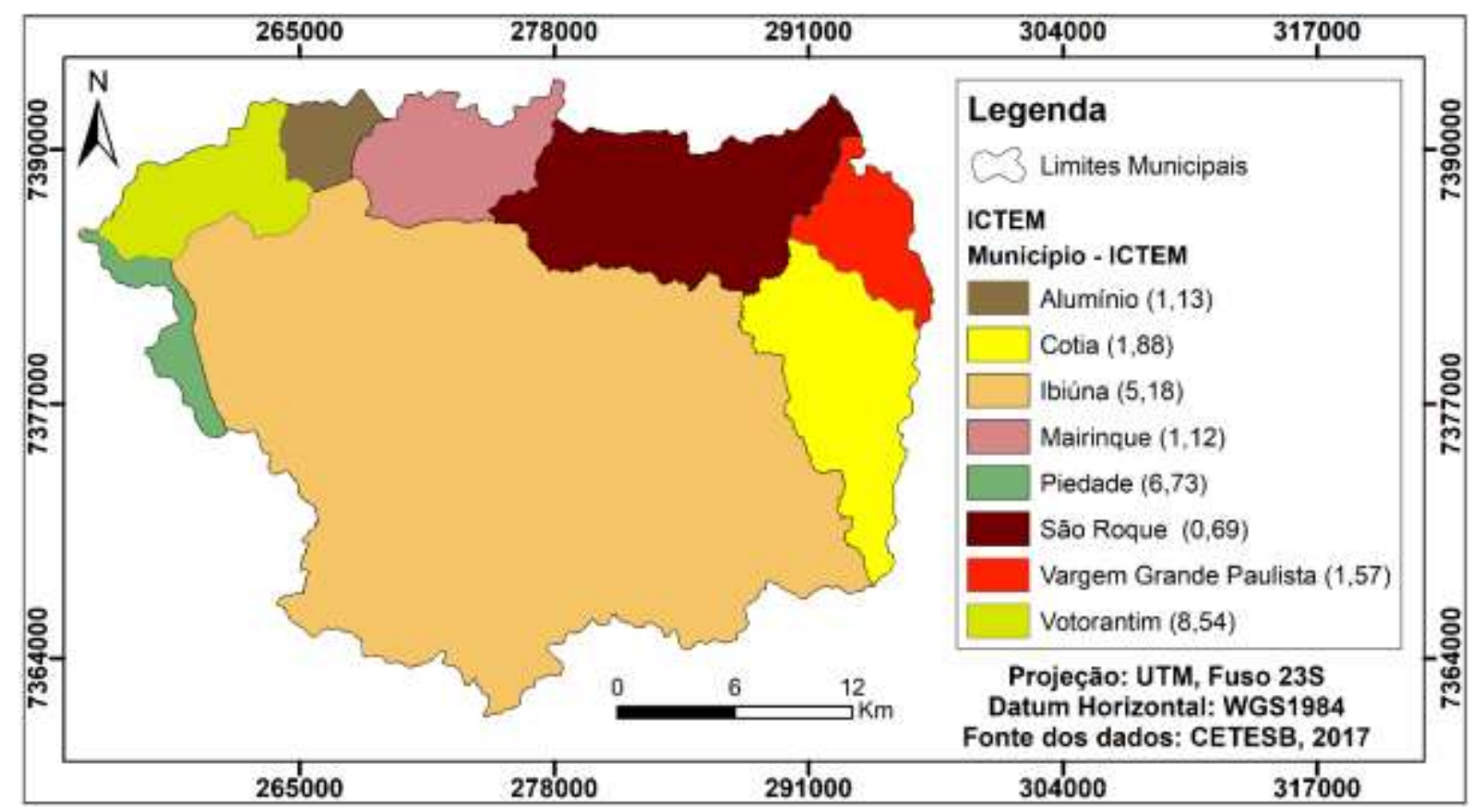

Fonte: Elaborado pelos autores, 2019

A partir da Figura 3 foi possível verificar que o município inserido na APA Itupararanga que apresenta o menor ICTEM é São Roque, com 0,69, seguido de Mairinque $(1,12)$, Alumínio $(1,13)$ e Cotia $(1,88)$, enquanto o município de Ibiúna, que possui a maior área inserida na APA, apresentou 5,18 de uma escala que varia entre 0 a 10, ou seja, possui apenas metade do valor desejado em função de sua extensão e representatividade na APA Itupararanga. Já o município de Piedade possui a menor área presente na APA, com um ICTEM de 6,73, e Votorantim é o município que atingiu o maior valor, sendo 8,54.

Os resultados detalhados do indicador foram dispostos na Tabela 2, sendo possível verificar que o município de São Roque, além de possuir o menor ICTEM, possui apenas $46 \%$ de coleta de esgoto, $0 \%$ de tratamento e uma carga poluidora de $4.333 \mathrm{~kg}$ de DBO/dia, sendo que $35 \%$ de seu território está inserido na APA Itupararanga, e a projeção da população urbana do município, segundo as estimativas do IBGE para o ano de 2018 é de um crescimento superior a $12 \%$. O município de Cotia também se destaca pelo baixo valor de ICTEM, com 1,88 e 25\% de sua área territorial na APA e pela maior carga poluidora de $\mathrm{kg}$ de DBO/dia, contribuindo com $12.839 \mathrm{~kg}$ diários. Em termos de território inserido na APA, o município de Vargem Grande Paulista possui $72 \%$, uma carga poluidora 
remanescente de $2.524 \mathrm{~kg}$ de DBO/dia resultante de $32 \%$ de coleta de esgoto e $28 \%$ de tratamento. Tendo em vista um crescimento populacional estimado em $20 \%$ para o ano de 2018, o município de Vargem Grande Paulista exerce uma elevada pressão na APA Itupararanga.

Tabela 2. Dados do Indicador de Coleta e Tratabilidade de Esgoto do Município (ICTEM) disponibilizadas pela CETESB (2017)

\begin{tabular}{|c|c|c|c|c|c|c|c|c|}
\hline \multirow{4}{*}{ Municípios } & \multirow{4}{*}{$\begin{array}{l}\text { Pop. } \\
\text { Urbana } \\
(2010)\end{array}$} & \multirow{4}{*}{$\begin{array}{c}\text { Pop. } \\
\text { estimada } \\
\text { para } \\
2018\left(^{\star}\right)\end{array}$} & \multirow{3}{*}{$\begin{array}{c}\text { Área do } \\
\text { município } \\
\text { na APA } \\
\left({ }^{* \star}\right)\end{array}$} & \multicolumn{3}{|c|}{ Esgoto } & \multirow{2}{*}{\multicolumn{2}{|c|}{$\begin{array}{c}\text { Carga } \\
\text { Poluidora } \\
\text { (Kg DBO/dia) }\end{array}$}} \\
\hline & & & & \multirow[t]{2}{*}{ Coleta } & \multirow[t]{2}{*}{ Tratado } & \multirow[t]{3}{*}{ Eficiência } & & \\
\hline & & & & & & & PT (1) & $\mathbf{R M}^{(2)}$ \\
\hline & & & \multicolumn{3}{|c|}{$\%$} & & & \\
\hline Alumínio & 15371 & 18484 & 20 & 70 & 5 & 0 & 830 & 830 \\
\hline Cotia & 237750 & 244694 & 25 & 49 & 43 & 0 & 12839 & 12839 \\
\hline Ibiúna & 27170 & 78262 & 55 & 43 & 100 & 90 & 1467 & 895 \\
\hline Mairinque & 37385 & 46852 & 24 & 75 & 0 & - & 2019 & 2019 \\
\hline Piedade & 25093 & 55149 & 3 & 68 & 96 & 90 & 1355 & 567 \\
\hline São Roque & 80,243 & 89943 & 35 & 46 & 0 & - & 4333 & 4333 \\
\hline $\begin{array}{l}\text { Vargem } \\
\text { Grande } \\
\text { Paulista }\end{array}$ & 50346 & 51702 & 72 & 32 & 28 & 80 & 2719 & 2524 \\
\hline Votorantim & 115302 & 121331 & 25 & 98 & 98 & 82 & 6226 & 1339 \\
\hline
\end{tabular}

Legenda: $\left({ }^{*}\right)$ Dados obtidos do Instituto Brasileiro de Pesquisas e Estatísticas (IBGE). Disponível em: https://www.ibge.gov.br/cidades. $\left({ }^{* *}\right)$ Dados obtidos do Plano de Manejo da APA Itupararanga (SÃO PAULO, 2010). (1) Potencial. (2) Remanescente.

Portanto, a análise do ICTEM evidenciou um cenário desfavorável sobre as condições de saneamento da APA. Ainda, a estimativa do IBGE sobre o crescimento populacional para o ano de 2018 (Tabela 2) prevê um de aumento de, aproximadamente, $15 \%$ da população residente nos municípios que compõem a APA, passando de 615.199 para 706.417 habitantes. Contudo, a perspectiva de melhoramento de saneamento dos municípios precisa ser acompanhada de perto, pois os relatórios de qualidade das águas interiores emitidos pela CETESB em 2017 ilustraram um painel pouco favorável e uma crescente deterioração da qualidade da água nos afluentes da APA Itupararanga.

\section{Parâmetros de qualidade da água da APA Itupararanga}

Para uma melhor representação dos resultados foram confeccionados gráficos no software Excel 2016 (Figuras 4 e 5) que permitiram a visualização dos resultados obtidos nos diferentes corpos d'água inseridos na APA, sendo utilizados 
os valores da média dos períodos analisados bem como o desvio padrão.

Figura 4. Parâmetros físicos, químicos, hidrobiológicos e microbiológicos analisados na APA Itupararanga, SP
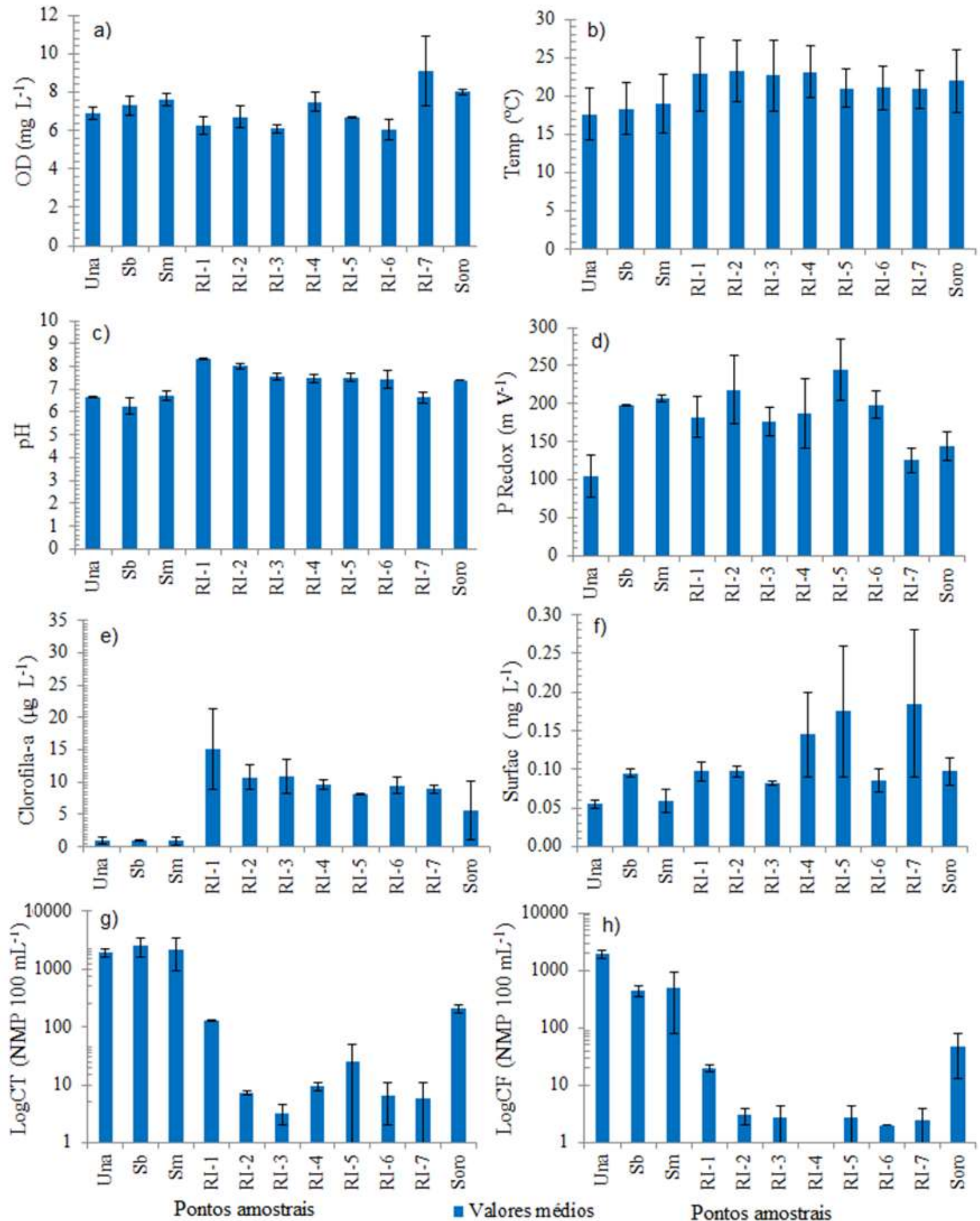

Fonte: Elaborado pelos autores, 2018 
Figura 5. Valores médios e desvio-padrão dos parâmetros físico-químicos analisados na APA Itupararanga, SP
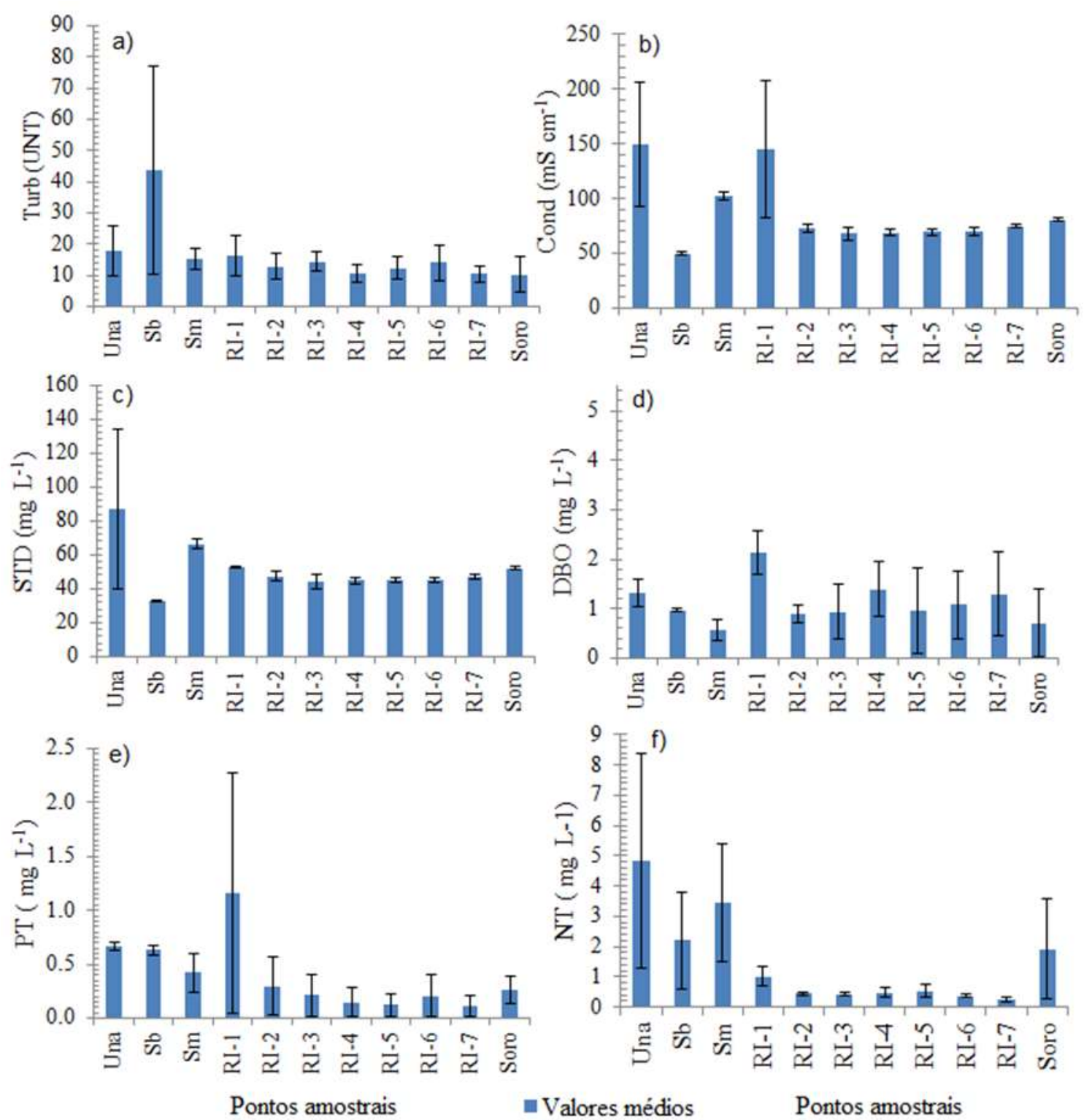

Fonte: Elaborado pelos autores, 2018

O oxigênio dissolvido (OD) pode ser considerado um dos mais importantes gases dissolvidos associados à dinâmica dos ecossistemas aquáticos (ESTEVES, 2011). Nesse sentido, é possível observar um elevado valor de OD no ponto amostral próximo à barragem do reservatório (RI-7) bem como o maior desvio padrão entre os períodos analisados (Figura 4a). De modo geral, todos os pontos apresentaram valores dentro do estabelecido pela Resolução CONAMA 357/05 ( $\geq 5$ $\mathrm{mg} \mathrm{L}^{-1}$ ).

A temperatura (Figura 4b) sofreu alteração ao longo dos pontos amostrais, 
devido a sazonalidade, bem como fatores relacionados à profundidade do corpo d'água, altitude e latitude. Pelo fato de a temperatura influenciar diretamente nas reações físico-químicas dos corpos d'água e nos processos metabólicos dos organismos aquáticos (MOURA; BOAVENTURA; PINELLI, 2010) é de suma importância o monitoramento deste parâmetro.

Quanto ao potencial hidrogeniônico $(\mathrm{pH})$ representado na Figura 4 (c), o ponto amostral $\mathrm{Sb}$ foi o único que apresentou um valor bem próximo ao mínimo estabelecido pela Resolução CONAMA 357/05. Valores baixos de pH podem ser indicativos de desequilíbrios ambientais, uma vez que influencia diretamente na fisiologia de muitas espécies (ROSA et al., 2015). Do mesmo modo, altos valores de $\mathrm{pH}$ podem favorecer a precipitação de alguns metais pesados na coluna d'água, dentre outras implicações (ROSA et al., 2015). Os pontos amostrais RI-1 e RI-2 apresentaram os valores mais elevados. Entretanto, de modo geral, todos os pontos amostrais apresentaram-se dentro dos limites preconizados pela Resolução CONAMA 357/05.

A capacidade de transferência de elétrons em ambientes aquáticos está associada às condições biogeoquímicas dos sedimentos e das substâncias presentes no meio (ESTEVES, 2011). Sendo assim, o potencial redox infere sobre a capacidade de oxirredução do ambiente. Os resultados evidenciaram um significativo contraste nos valores obtidos (Figura 4d), sendo o Una o ponto amostral com menor valor médio entre os rios formadores, e os pontos RI-2, RI-5 e RI-6 inseridos no reservatório apresentaram os valores médios mais elevados.

Todos os pontos amostrais apresentaram valores abaixo do máximo permitido pela Resolução CONAMA 357/05 para a clorofila-a (Figura 4e). Os pontos inseridos em ambientes lóticos compreendendo os rios formadores do reservatório de Itupararanga apresentaram valores mais baixos. Contudo, a partir do represamento, os valores médios obtidos tenderam a aumentar, sendo o maior valor médio obtido bem como o maior desvio padrão no RI-1, uma vez que este ponto recebe o despejo dos rios formadores.

O estudo também contemplou a análise de surfactantes nos pontos amostrais (Figura 4f), sendo que nenhum ponto amostral obteve valor superior ao preconizado pela legislação; no entanto, os pontos inseridos no reservatório (RI-4), (RI-5) e (RI-7) apresentaram os maiores valores médios e desvio-padrão. De acordo com Santos et al. (2012), o uso abundante de detergentes pela população pode alterar a tensão superficial da água, o que confere aos surfactantes um potencial risco para a biota, podendo, ainda, comprometer a quantidade de oxigênio dissolvido nos corpos 
hídricos.

Os parâmetros microbiológicos expressos na Figura 4(g) e (h) também foram analisados e os resultados demonstraram que os pontos amostrais inseridos na cabeceira do reservatório, ou seja, os rios formadores do reservatório apresentaram os valores médios mais elevados de coliformes totais e coliformes fecais. Já os pontos inseridos no reservatório apresentaram valores significativamente mais baixos, com exceção do RI-1, que recebe a carga dos rios formadores. Os valores elevados encontrados na cabeceira bem como no RI-1 são oriundos do aporte de matéria orgânica fecal resultante do despejo de efluentes domésticos pelos municípios inseridos na cabeceira da APA Itupararanga, evidenciados pelos baixos valores de ICTEM dos municípios.

A partir da Figura 5(a) foi possível observar que o ponto amostral inserido no Rio Sorocabuçu (Sb) obteve o valor médio mais elevado, bem como o maior desviopadrão dentre os pontos amostrados. No entanto, apesar do valor mais elevado do $\mathrm{Sb}$, todos os pontos mantiveram-se dentro dos limites estabelecidos pela resolução CONAMA $357 / 05$ de até 100 UNT. A turbidez (Turb) refere-se às partículas orgânicas e inorgânicas presentes na água que interferem na passagem da luz, conferindo à água um aspecto turvo (CUNHA et al., 2013; SILVA et al., 2017b). No entanto, os pontos amostrados não apresentaram valores que pudessem acarretar danos à biota; todavia, por se tratar de um parâmetro de relevância elevada, deve ser constantemente monitorado.

A condutividade elétrica (Figura 5b) apresentou valores abaixo do recomendado pela CETESB em todos os pontos amostrais, sendo inferiores a 100 $\mu S \mathrm{~cm}^{-1}$. No entanto, os maiores valores médios e desvio-padrão foram obtidos no Rio Una e no ponto localizado na diluição (RI-1). A Cond expressa à quantidade de sais presentes na água, podendo inferir sobre a poluição dos corpos d'água uma vez que está associado à quantidade de sólidos dissolvidos na água (TIECHER et al., 2013).

Os sólidos totais dissolvidos (STD) (Figura 5c) dos pontos amostrados apresentaram valores bem abaixo do determinado pela resolução CONAMA 357/05. Dentre os pontos amostrados, o Rio Una foi o que apresentou o maior valor médio e desvio-padrão. Os STD representam um parâmetro que exerce grande impacto nos organismos aquáticos. Com exceção dos gases dissolvidos, qualquer contaminante que aporte os corpos d'água agrega a eles partículas sólidas. Valores elevados podem ocasionar significativos danos aos peixes, por exemplo, prejudicando a desova e a disponibilidade de alimentos. Ainda podem desencadear processos de 
decomposição anaeróbia nos corpos d'água por sedimentação de material orgânico e bactérias no fundo dos rios (TIECHER et al., 2013; SILVA et al., 2017b). Portanto, recomenda-se o monitoramento pontual dos recursos hídricos da APA Itupararanga e ações de controle de desmatamento de suas margens de modo a evitar esses potenciais impactos na biota.

Em relação à demanda bioquímica de oxigênio (DBO), o ponto amostral que apresentou o maior valor foi o RI-1 (Figura $5 \mathrm{~d}$ ), inserido no ponto amostral localizado na diluição dos rios formadores dentro do reservatório. Esse ponto amostral, por se tratar da confluência dos rios Una, Sorocabuçu e Sorocamirim, recebe uma elevada carga orgânica. Segundo Von Sperling (2005), a análise da DBO representa a quantidade indireta de matéria orgânica presente no corpo d'água, e proporciona uma estimativa da quantidade de OD que será consumida para que ocorra a estabilização da matéria orgânica. Deste modo, todos os pontos amostrais apresentaram-se dentro dos valores preconizados pela Resolução CONAMA 357/05.

Os resultados provenientes das análises de fósforo total (Figura $5 e$ ) revelaram altos valores nos rios formadores do reservatório de Itupararanga, sendo que os valores obtidos nos pontos amostrais Una, Sb e Sm estão acima do permitido pela legislação (CONAMA 357/05). Elevados valores não conferem problemas de ordem sanitária aos corpos d'água; no entanto, o fósforo é um dos principais elementos responsáveis pelo crescimento de organismos fotossintetizantes, sendo um potencial causador de processos relacionados à eutrofização dos ambientes aquáticos (CUNHA et al., 2013; SILVINO; BARBOSA, 2015).

Dentre os pontos amostrados, os rios formadores do reservatório apresentaram elevados valores de NT (Figura 3f), destacando o rio Una com o maior desvio-padrão entre os pontos amostrados. De acordo com a Resolução CONAMA $357 / 05$, os valores máximos de nitrogênio total amoniacal variam em razão do $\mathrm{pH}$. O nitrogênio, assim como o fósforo, é um elemento essencial para os organismos aquáticos, podendo atuar como um elemento limitante à produção primária (SILVINO; BARBOSA, 2015).

\section{Índices de qualidade das águas}

Em posse dos resultados dos parâmetros de qualidade da água apresentados, foram elaborados os índices de qualidade de água (Figura 6). Os resultados revelaram que todos os pontos amostrais da Figura 6(a) estão inseridos nas faixas consideradas Boa e Ótima para ambos os períodos estudados. No entanto, observou-se uma tendência crescente dos valores de IQA, partindo dos rios 
formadores (Una, Sorocabuçu e Sorocamirim) que apresentaram valores mais baixos em ambos os períodos, sendo IQA igual a 60 para o Una e Sb, e IQA igual a 72 para o Sm no período chuvoso. Já no período seco, o Una apresentou IQA igual a 62, Sb um IQA igual a 68 e Sm (IQA=69), demonstrando que, no período chuvoso, os rios formadores obtiveram valores mais baixos devido a influência do escoamento superficial, com valores mais expressivos para o rio Una, o que pode ser atribuído à urbanização evidenciada nas classes de uso da terra (áreas ocupadas) mapeadas nos entornos dos respectivos pontos amostrados.

Figura 6. Resultados sazonais do Índice de Qualidade das Águas (IQA) e Índice de Estado Trófico (IET) dos principais cursos de água da APA Itupararanga
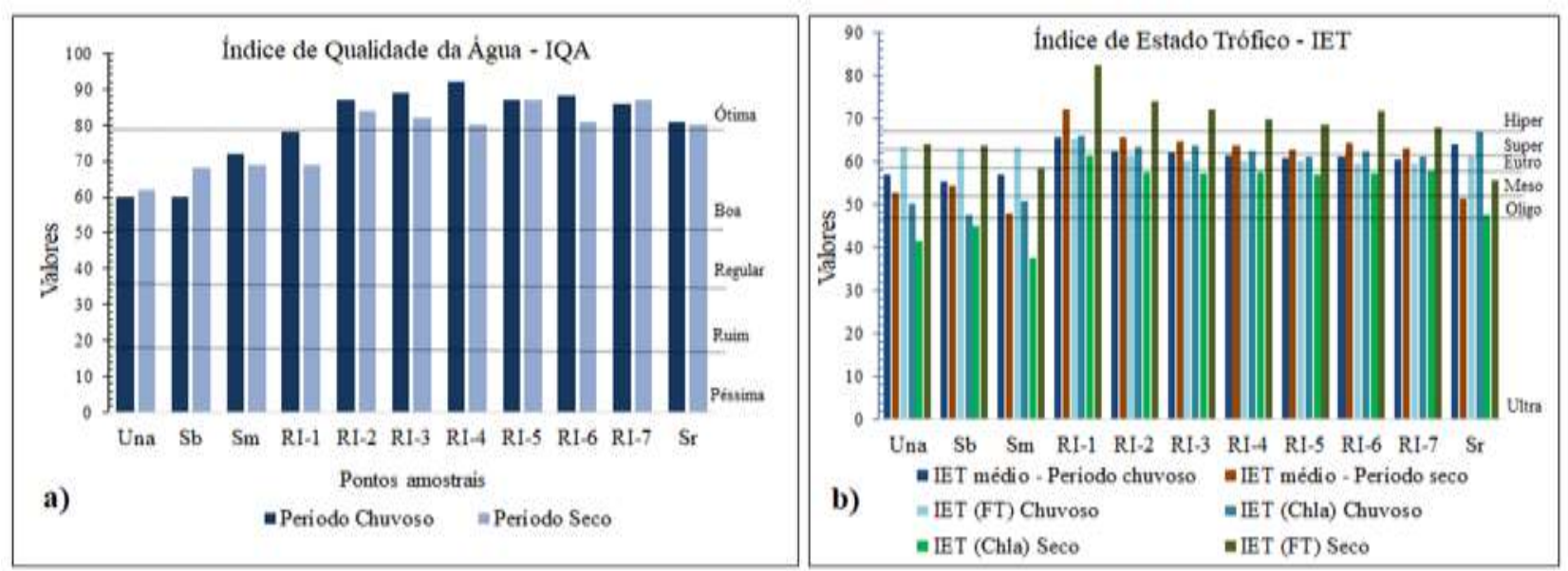

Fonte: Elaborado pelos autores, 2018

Legenda: Nível de qualidade classificado como Ótima: $79<\mathrm{IQA} \leq 100$, Boa: $51<$ IQA $\leq 79$, Regular: $36<$ IQA $\leq 51$, Ruim: $19<\mathrm{IQA} \leq 36$, Muito Ruim: IQA $\leq 19$. Valores atribuídos ao índice de estado trófico (média): Ultraoligotrófico $=\mathrm{IET} \leq 47$, Oligotrófico $=47<\mathrm{IET} \leq 52$, Mesotrófico $=52<\mathrm{IET} \leq 59$, Eutrófico $=59<\mathrm{IET} \leq 63$, Supereutrófico $=63<\mathrm{IET} \leq 67$, Hipereutrófico $=\mathrm{IET}>67$.

Dentre os pontos amostrados no reservatório de Itupararanga, o ponto amostral (Rl-1) foi o que apresentou os valores mais baixos para ambos os períodos analisados, sendo IQA igual a 78 para o período chuvoso e IQA igual a 69 para o período seco. No período chuvoso, o IQA apresentou um valor crescente à jusante do ponto Rl-1, que recebe toda a carga proveniente da diluição dos rios da cabeceira. No entanto, a partir do RI-5 o valor do IQA tende a decrescer ano sentido da barragem no período chuvoso, o que sugere a entrada de cargas poluidoras próximas aos pontos amostrais provenientes do uso do entorno. No período seco é possível observar que o pior valor também foi no ponto amostral onde ocorre a diluição dos rios da cabeceira.

O índice de estado trófico (IET) Figura 6(b) apresentou os valores mais 
elevados no ponto amostral referente à confluência dos afluentes da cabeceira, sendo os IET médio do período chuvoso classificado como supereutrófico e hipereutrófico no período seco. Os valores mais elevados do IET médio prevaleceram no período seco para todos os pontos do reservatório; enquanto no ponto amostrado no rio Sorocaba (Sr), o IET médio apresentou valores mais elevados no período chuvoso, assim como nos rios da cabeceira.

Ainda, na Figura 6(b), é possível observar valores predominantes do IET do fósforo total (FT) em relação ao IET da clorofila (Chla) para os pontos da cabeceira (Una, Sb, Sm) e RI-1 em ambos os períodos estudados. Já o Sr apresentou o mesmo perfil dos pontos amostrados no reservatório, com valores mais altos do IET (Chla) no período chuvoso e, no período seco, prevalência do IET (FT). Isso evidencia que o rio Sorocaba no ponto amostrado sofre uma influência direta do represamento da água. No entanto, os valores elevados do IET (Chla) podem impactar significativamente na qualidade da água do reservatório que é utilizado para abastecimento público, pois é um indicativo da presença de algas fotossintetizantes no reservatório que podem ser altamente nocivas à saúde humana.

Nos pontos do reservatório respectivo ao período chuvoso, os valores de clorofila foram superiores ao de fósforo em todos os pontos amostrados. Já no período seco, a situação foi inversa, onde todos os pontos do reservatório apresentaram valores superiores para o IET do fósforo. Entretanto, observa-se uma diferente dinâmica relacionada aos regimes lóticos e lênticos quanto à concentração de clorofila e fósforo total.

Estudos anteriores realizados no reservatório já apontavam o aumento crescente do estado trófico da água do reservatório, como os realizados por Taniwaki et al. (2013), Pedrazzi et al. (2014), Frascareli et al. (2015) e Rosa et al. (2015). Todavia, os resultados apresentados sugerem fortes impactos advindos dos diversos usos do solo no entorno do reservatório de Itupararanga bem como nos pontos amostrados na cabeceira, nos principais rios formadores, como o Una, Sorocabuçu e Sorocamirim.

\section{Resultados das análises estatísticas multivariadas}

A análise multivariada de componentes principais (ACP) tem sido amplamente utilizada na análise de dados ambientais (MOURA; BONVENTURA; PINELLI, 2010; FRASCARELI et al., 2015; HONGYU; SANDANIELO; OLIVEIRA JÚNIOR, 2015; MENEZES et al., 2016). Partindo desta premissa, foram realizadas as análises de 
componentes principais dos parâmetros de qualidade da água nos dois períodos (Figura 7), onde o componente 1 explicou 44\% das correlações no período chuvoso, enquanto o componente 2 explicou $21 \%$.

\section{Figura 7. Análise de Componentes Principais (ACP) do período chuvoso dos pontos amostrados na APA Itupararanga}

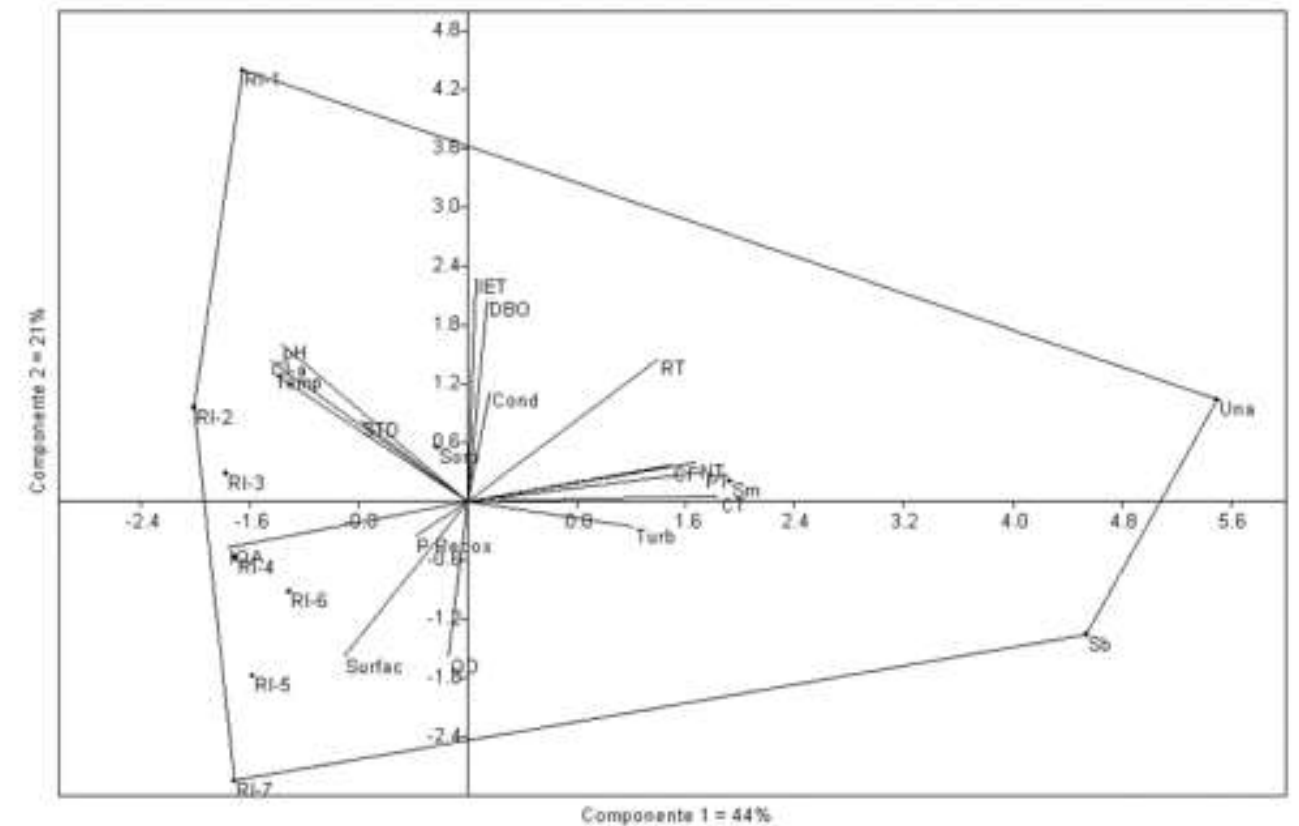

Fonte: Elaborado pelos autores, 2018

Legenda: Una - Rio Una. Sb - Rio Sorocabuçu. Sm - Rio Sorocamirim. RI Reservatório de Itupararanga. $\mathrm{pH}$ - potencial hidrogeniônico. OD - oxigênio dissolvido. DBO - demanda bioquímica de oxigênio. NT - nitrogênio total. FT - fósforo total. RT - resíduo total. Temp - temperatura. Pot Redox - potencial redox. Coli Termo - coliformes termotolerantes. Coli Totais - coliformes totais. STD - sólidos totais dissolvidos. $\mathrm{Cl}-\mathrm{a}$ - clorofila a. Cond - condutividade elétrica.

As correlações positivas mais significativas foram observadas entre os parâmetros de qualidade da água RT, CT, CF, PT e NT, principalmente para os pontos amostrais inseridos na cabeceira, contemplando os Rios Sorocamirim (Sm), Una e Sorocabuçu (Sb). Já os parâmetros de qualidade $\mathrm{pH}, \mathrm{Cl}-\mathrm{a}$, Temp, STD, P Redox, Surfactantes e OD foram mais influenciados pelos pontos amostrais inseridos no reservatório, correspondendo ao ambiente lêntico.

A ACP do período seco pode ser observada na Figura 8, onde o componente 1 explicou $43 \%$ das correlações do período seco, enquanto o componente 2 explicou $21 \%$. Foi possível verificar um padrão distinto em relação às variáveis analisadas e o período sazonal, sendo que, para os pontos amostrais inseridos na cabeceira (Sb), (Una) e (Sm) apresentaram correlações mais expressivas com as variáveis CF, CT, NT e STD. O ponto amostral inserido no Rio Sorocaba demonstrou um padrão semelhante ao ambiente lêntico, provavelmente pelo fato de sofrer influência direta 
do regime do reservatório.

\section{Figura 8. Análise de Componentes Principais (ACP) do período seco dos parâmetros de qualidade da água analisados na APA ltupararanga}

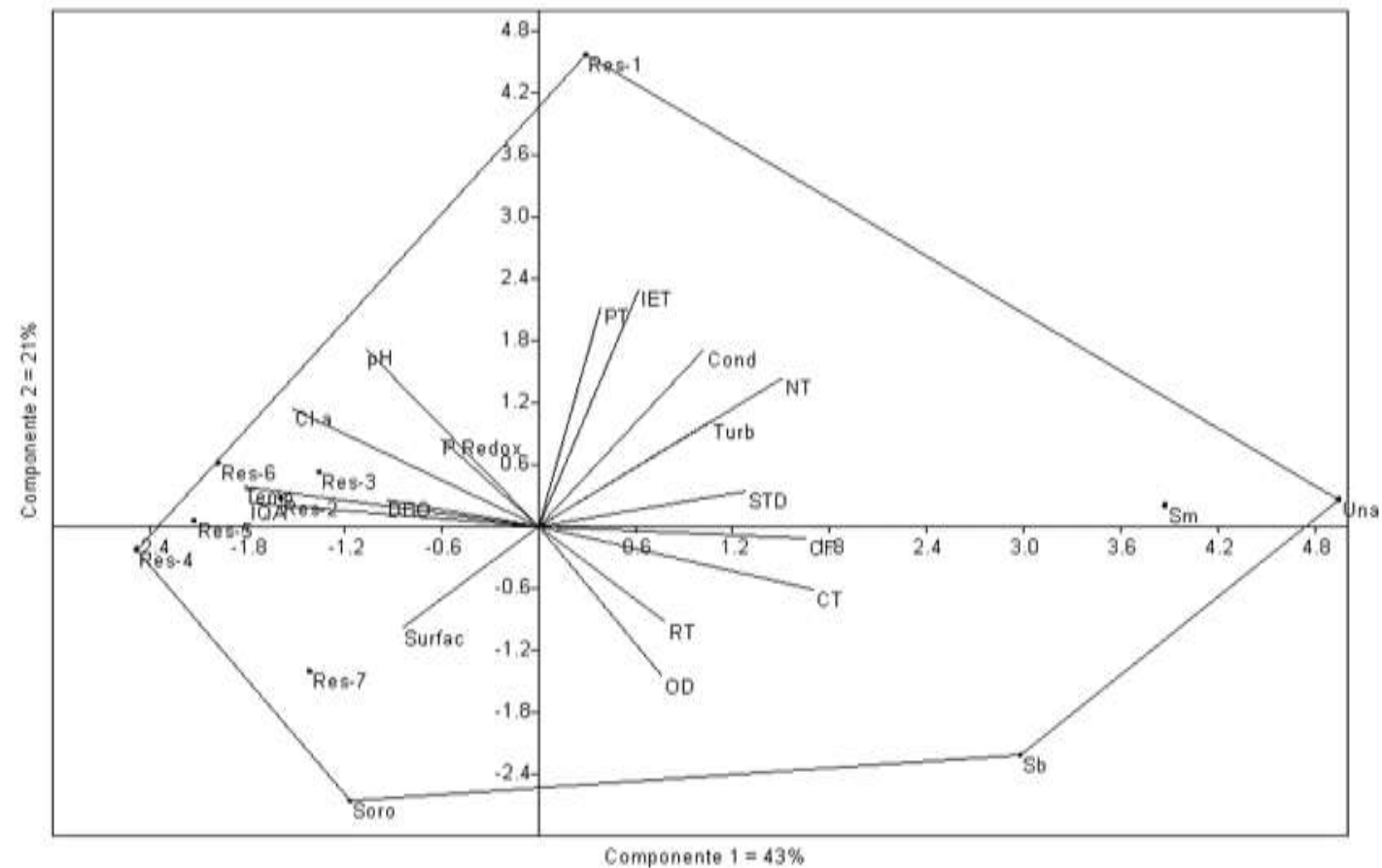

Fonte: Elaborado pelos autores, 2018

Legenda: Una - Rio Una. Sb - Rio Sorocabuçu. Sm - Rio Sorocamirim. RI Reservatório de Itupararanga. $\mathrm{pH}$ - potencial hidrogeniônico. OD - oxigênio dissolvido. DBO - demanda bioquímica de oxigênio. NT - nitrogênio total. FT - fósforo total. RT - resíduo total. Temp - temperatura. Pot Redox - potencial redox. Coli Termo - coliformes termotolerantes. Coli Totais - coliformes totais. STD - sólidos totais dissolvidos. Cl-a - clorofila a. Cond - condutividade elétrica.

A partir da Análise de Componentes Principais foi possível inferir que os parâmetros de qualidade de água apresentam características distintas em função do ambiente aquático, com correlações mais expressivas para as variáveis coliformes fecais, coliformes totais e nitrogênio total em ambos os períodos analisados.

No entanto, o fósforo total apresentou maior correlação no período chuvoso, sugestivo do aporte de nutrientes aos corpos de água característico desse período devido ao deflúvio pluvial. Isso pode ser agravado com o processo de adubação concernente às culturas agrícolas que foram mapeadas em grandes extensões na APA Itupararanga e, caso não haja práticas adequadas de manejo e conservação do solo nessas respectivas áreas, o arraste de sedimentos para os corpos hídricos pode comprometer a qualidade da água. Nos estudos realizados por Zolin et al. (2011) isso foi verificado, uma vez que os autores analisaram a perda de solos em quatorze diferentes cenários de usos da terra, sendo as maiores perdas constatadas pela ausência de práticas adequadas de manejo. Ainda, Hernani et al. (2002) 
verificaram que os custos associados à poluição difusa em bacias hidrográficas que culmina no carreamento de sedimentos aos corpos de água, podem causar prejuízos superiores a um bilhão de dólares para o tratamento da água destinada ao abastecimento público.

A análise cluster (Figura 9) foi realizada de modo a inferir sobre a influência do uso e ocupação do solo nos parâmetros de qualidade da água analisados na APA Itupararanga.

\section{Figura 9. Dendrograma do período chuvoso da APA Itupararanga pelo Ward's Method e quadrado da distância Euclidiana}

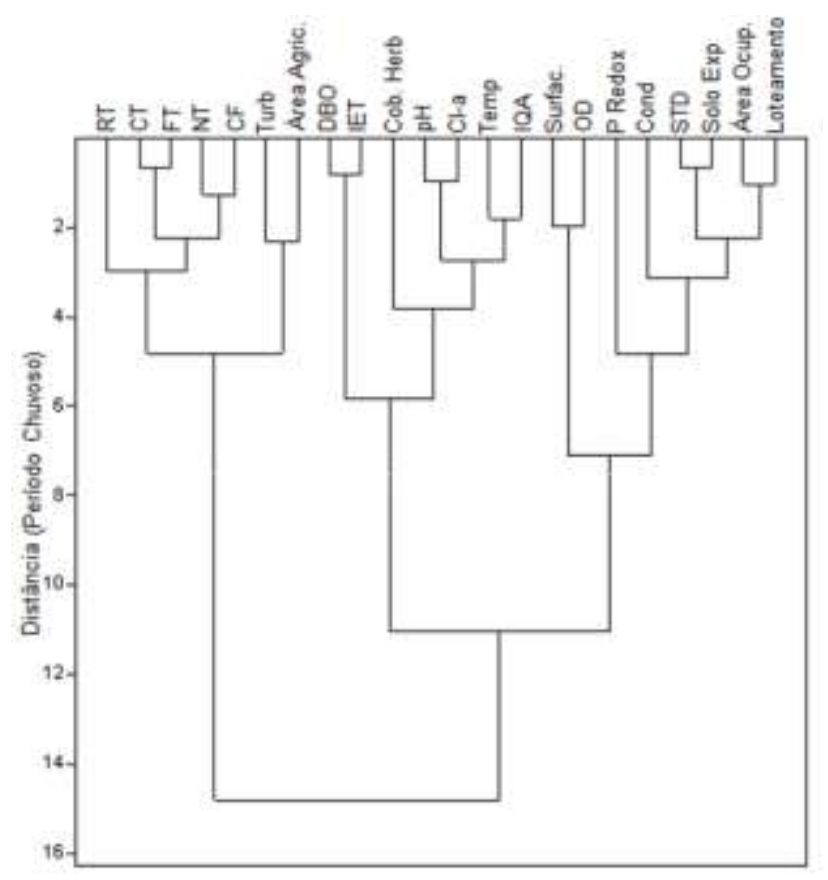

Fonte: Elaborado pelos autores, 2018

A partir da Figura 9 foi possível verificar que no período chuvoso a área agrícola influenciou os parâmetros de qualidade de água referente à turbidez (Turb) que, por sua vez, influenciaram nos parâmetros de coliformes fecais (CF), nitrogênio total (NT), fósforo total (FT), coliformes totais (CT) e resíduos totais (RT).

As áreas com cobertura herbácea-arbustiva, que contemplam às áreas de pastagem e espécies forrageiras, influenciaram nos índices de qualidade IQA e IET, além dos parâmetros de qualidade da água como a temperatura (Temp), clorofila-a $(\mathrm{Cl}-\mathrm{a})$, potencial hidrogeniônico $(\mathrm{pH})$ e demanda bioquímica de oxigênio (DBO). Já as áreas com loteamento, área ocupada e solo exposto, influenciaram as variáveis referentes aos sólidos totais dissolvidos (STD), condutividade (Cond), potencial redox ( $P$ Redox), oxigênio dissolvido (OD) e surfactantes (Surfac). Entretanto, esses resultados são bastante condizentes com os efeitos do escoamento superficial e, 
também, do deflúvio agrícola característico do período chuvoso, que podem aportar substâncias e elementos para os corpos de água (TIECHER et al., 2013). O dendrograma do período seco foi expresso na Figura 10.

Figura 10. Dendrograma do período seco da APA Itupararanga pelo Ward's Method e quadrado da distância Euclidiana

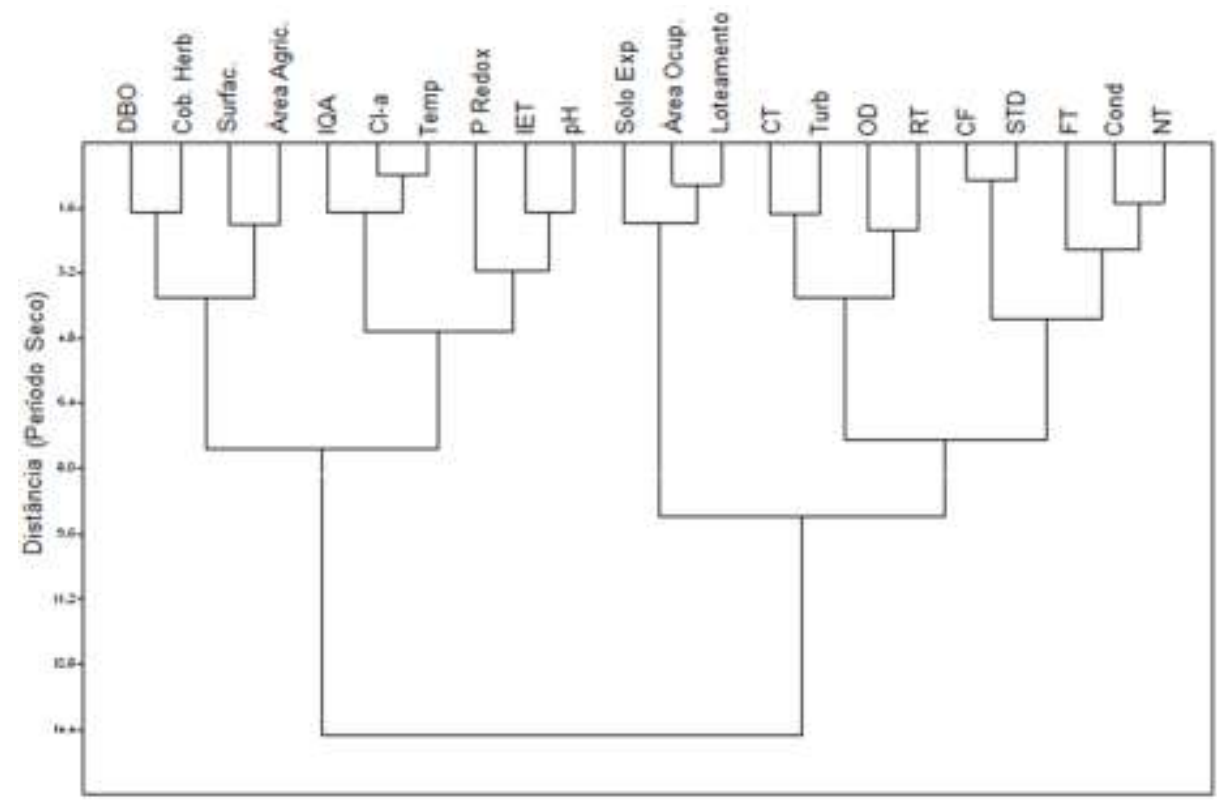

Fonte: Elaborado pelos autores, 2018

No período seco (Figura 10) foi possível observar um agrupamento diferenciado, onde as variáveis do uso da terra como a área agrícola e as coberturas herbácea-arbustivas influenciaram nos índices IQA e IET bem como nos parâmetros de qualidade de água referentes à $\mathrm{Cl}-\mathrm{a}$, Temp, $\mathrm{P}$ Redox $\mathrm{e} \mathrm{pH}$, enquanto o loteamento, área ocupada e solo exposto influenciaram nos parâmetros referentes aos CT, Turb, RT, CF, FT e NT, evidenciando uma maior concentração desses elementos no período seco.

A análise de agrupamento é amplamente utilizada na avaliação da qualidade da água envolvendo o uso da terra bem como outros aspectos relacionados a uma bacia hidrográfica. Menezes et al. (2016) utilizaram a análise de agrupamento (cluster) em seu estudo na bacia hidrográfica do Rio Ribeirão Vermelho (MG), com o intuito de otimizar os pontos de monitoramento de qualidade da água da bacia hidrográfica, reportando que essa abordagem pode diminuir os custos operacionais relacionados ao monitoramento da qualidade de água. Enquanto os estudos realizados por Moura, Bonventura e Pinelli (2010) diferenciaram o comportamento das águas da bacia hidrográfica do Gama (DF), inferindo sobre as condições anômalas relacionadas aos elementos que aportaram os cursos de água da bacia 
hidrográfica.

\section{Considerações finais}

O uso de ferramentas de geoprocessamento no mapeamento do uso e ocupação da terra, associados à coleta de dados in situ e ferramentas estatísticas de dados multivariados, se mostrou altamente eficaz na análise da influência dos usos diversificados na qualidade da água dos principais afluentes da APA Itupararanga, fornecendo informações substanciais ao que tange as principais classes de usos com maior potencial de deterioração da qualidade da água.

A utilização de índices de qualidade da água permitiu inferir sobre o painel geral da qualidade da água sazonalmente na APA Itupararanga, sendo encontrados bons resultados para o índice de qualidade das águas (IQA), que contempla as variáveis mais significativas para fins de abastecimento público, no qual todos os pontos amostrados sazonalmente se apresentaram na classe boa e excelente. No entanto, o IQA é um indicador voltado para a análise da qualidade da água com vistas ao abastecimento público, e diante dos pesos atribuídos aos parâmetros serem bastante diluídos e não contemplarem variáveis que podem ser nocivas à biota, como os elementos metálicos, por exemplo, podem mascarar os resultados e apresentar valores superestimados.

O índice de estado trófico (IET), que avalia os níveis de trofia nos corpos d'água, apresentou variações relacionadas à dinâmica hídrica dos corpos de água, onde os rios amostrados na área de cabeceira da APA Itupararanga obtiveram valores de IET do fósforo total mais elevados no período chuvoso, enquanto os pontos amostrados no reservatório indicaram maior influência do período seco no IET (FT). Ainda, foi possível verificar que o rio Sorocaba apresentou valores similares de IET aos encontrados no reservatório. Em relação ao IET médio, os pontos inseridos na cabeceira tiveram valores mais elevados no período chuvoso (mesotróficos); enquanto os pontos do reservatório apresentaram valores mais elevados no período seco, com destaque para o ponto inserido na diluição dos afluentes da cabeceira (RI-1) com os valores mais elevados em todas as classes de IET contempladas no estudo.

Entre os parâmetros de qualidade da água analisados, foram obtidos elevados valores para a variável química relacionadas ao fósforo total (CONAMA 357/05) nos dois períodos analisados. Enquanto os parâmetros estabelecidos pela CETESB, a condutividade elétrica e o nitrogênio total se destacaram com os valores mais elevados em ambos os períodos. 
O parâmetro microbiológico referente aos coliformes totais e fecais também apresentaram elevados valores, principalmente nos rios formadores e no ponto de diluição do reservatório. Esse resultado é justificado pelo mapeamento realizado das classes de uso e ocupação da terra, bem como no levantamento do indicador de coleta e tratamento de esgoto dos municípios, que revelou valores aquém do esperado para todos os municípios inseridos na APA Itupararanga, com exceção de Votorantim, que obteve o maior índice nesta avaliação.

Os usos e ocupação da terra mapeados no estudo evidenciaram grandes extensões de classes agrícolas e coberturas herbácea-arbustivas na APA Itupararanga, sendo o município de lbiúna o maior detentor dessas respectivas classes. Portanto, em razão da análise pormenorizada das classes de uso e ocupação da terra realizada no presente estudo, é possível inferir que o município de Ibiúna exerce uma elevada pressão na qualidade da água do reservatório devido as áreas agricultáveis e urbanização próximas aos cursos de água. Não obstante, os demais municípios inseridos na APA Itupararanga também contribuem negativamente na qualidade da água, pois não possuem um sistema eficiente de coleta e tratamento de esgoto sanitário, além de possuírem uma elevada urbanização, que poderá se intensificar diante da projeção populacional para os próximos anos, exigindo, assim, cada vez mais recursos naturais para suprir a demanda.

Entretanto, é imprescindível a articulação dos municípios inseridos na cabeceira da APA Itupararanga para contenção das fontes de poluição difusas e pontuais que possam aportar os recursos hídricos da bacia hidrográfica. É importante salientar que a avaliação realizada no presente estudo foi pontual, necessitando, assim, de um contínuo acompanhamento e monitoramento da qualidade da água.

\section{Referências Bibliográficas}

AMERICAN PUBLIC HEALTH ASSOCIATION - APHA. Standard methods for the examination of water and wastwater. Washington. 1999.

BEGHELLI, F. G. S.; SANTOS, A. C. A. D.; URSO-GUIMARÃES, M. V.; CALIJURI, M. D. C. Spatial and temporal heterogeneity in a subtropical reservoir and their effects over the benthic macroinvertebrate community. Acta Limnologica Brasiliensia, v. 26, n. 3, p. 306317, 2014. http://dx.doi.org/10.1590/S2179-975X2014000300010

BEU, S. E.; MISATO, M. T.; HAHN, C. M. APA de Itupararanga. In: BEU, S. E; SANTOS, A. C. A.; CASALI, S. (Org.). 2011. Biodiversidade na APA de Itupararanga: Condições atuais e perspectivas futuras. Secretaria de Meio Ambiente. São Carlos: UFSCAR/FF/CCR, 2011.

CETESB. Companhia Ambiental do Estado de São Paulo. Relatório de Qualidade das Águas Interiores do Estado de São Paulo. São Paulo, SP. 2017. 
https://cetesb.sp.gov.br/aguas-interiores/wp-content/uploads/sites/12/2018/06/Relat\%C3\% B3rio-de-Qualidade-das-\%C3\%81guas-Interiores-no-Estado-de-S\%C3\%A3o-Paulo-2017.pdf COELHO, A. S.; MARENZI, R. C.; IZA, O. B.; SOUZA, V. A. C.; LONGARETE, C. Análise da estrutura espacial e funcional da paisagem aplicada ao planejamento da conservação da natureza no município de Itajaí, Santa Catarina, Brasil. Geosul, v. 33, n. 66, p. 304-327, 2018. https://doi.org/10.5007/2177-5230.2018v33n66p304

CONCEIÇÃO, F. T.; SARDINHA, D. S.; GODOY, L. H.; FERNANDES, A. M.; PEDRAZZI, F. J. M. Influência sazonal no transporte específico de metais totais e dissolvidos nas águas fluviais da bacia do Alto Sorocaba (SP). Geochimica Brasiliensis, 2015.

CONSELHO NACIONAL DO MEIO AMBIENTE - CONAMA (Brasil). Resolução no 357 de 2005. Brasília, 2005.

CUNHA, R. W.; GARCIA JR, M. D.; ALBERTONI, E. F.; PALMA-SILVA, C. Qualidade de água de uma lagoa rasa em meio rural no sul do Brasil. Revista Brasileira de Engenharia Agrícola e Ambiental-Agriambi, v. 17, n. 7, 2013.

ESTEVES, F. A. Fundamentos da limnologia. 3. ed. Rio de Janeiro: Interciência, 2011.

FRASCARELI, D.; BEGHELLI, F. G. S.; CARDOSO-SILVA, S.; MOSCHINI CARLOS, V. Heterogeneidade espacial e temporal de variáveis limnológicas no reservatório de Itupararanga associadas com o uso do solo na Bacia do Alto Sorocaba-SP. Ambiente \& Água-An Interdisciplinary Journal of Applied Science, v. 10, n. 4, 2015.

HONGYU, K.; SANDANIELO, V. L. M.; OLIVEIRA JUNIOR, G. J. Análise de Componentes Principais: Resumo Teórico, Aplicação e Interpretação. E\&S Engineering and Science, v. 5, n. 1, p. 83-90, 2016. http://dx.doi.org/10.18607/ES201653398

HERNANI, L. C.; FREITAS, P. L.; PRUSKI, F. F.; DE MARIA, I. C.; CASTRO FILHO, C.; LANDERS, J. N. A erosão e seu impacto. In: MANZATTO, C. V.; FREITAS JUNIOR, E.; PERES, J. R. R (ed.). Uso agrícola dos solos brasileiros. Rio de Janeiro: Embrapa Solos, p. 47-60, 2002.

LAMPARELLI, M. C. Grau de trofia em corpos d'água do estado de São Paulo: avaliação dos métodos de monitoramento. 2004. 235p. Tese (Doutorado) - Instituto de Biociências da Universidade de São Paulo: Departamento de Ecologia, 2004.

MENEZES, J. P. C.; BITTENCOURT, R. P.; FARIAS, M. S.; BELLO, I. P.; FIA, R.; OLIVEIRA, L. F. C. Relationship between patterns of use and occupation of soil and water quality in an urban watershed. Engenharia Sanitária e Ambiental, v. 21, n. 3, p. 519-534, 2016. http://dx.doi.org/10.1590/S1413-41522016145405

MOURA, L. H. A.; BOAVENTURA, G. R.; PINELLI, M. P. A qualidade de água como indicador de uso e ocupação do solo: Bacia do Gama-Distrito Federal. Química nova, v. 33, n. 1, p. 97-103, 2010.

OLIVEIRA, R. A.; SILVA, D. C. C.; SIMONETTI, V. C.; STROKA, E. A. B.; SABONARO, D. Z. Proposição de Corredor Ecológico entre duas Unidades de Conservação na Região Metropolitana de Sorocaba. Revista do Departamento de Geografia, v. 32, p. 61-71, 2016. http://dx.doi.org/10.11606/rdg.v32i0.116467

PEDRAZZI, F. J. M.; CONCEIÇÃO, F. T.; SARDINHA, D. S.; MOSCHINI-CARLOS, V.; POMPÊO, M. Avaliação da qualidade da água no reservatório de Itupararanga, Bacia do Alto Sorocaba (SP). Revista Geociências, v. 33, n. 1, 2014.

PEREIRA, R.; BISSANI, K. A regularização do parcelamento do solo de loteamentos públicos: um estudo a partir do projeto do loteamento de interesse social Vila Betinho em Chapecó/SC. Revista Brasileira de Políticas Públicas, v. 7, n. 2, 2017.

PIROLI, E. L. Água: por uma nova relação. Jundiaí: Paco Editorial, 2016.

POLETO, C. Bacias hidrográficas e recursos hídricos. Rio de Janeiro: Interciência, 2014. SALLES, M. H. D.; CONCEIÇÃO, F. T.; ANGELUCCI, V. A.; SIA, R.; PEDRAZZI, F. J. M.; CARRA, T. A.; NAVARRO, G. R. B. Avaliação Simplificada de Impactos Ambientais na Bacia do Alto Sorocaba (SP). Revista de estudos ambientais. v. 10, n. 1, p. 6-20. 2008.

SANTOS, S.; OLIVEIRA, L. C.; SANTOS, A.; ROCHA, J. C.; ROSA, A. H. Poluição aquática. In: ROSA, A. H.; FRACETO, L. F.; CARLOS, V. M. (Org.). Meio ambiente e sustentabilidade. Porto Alegre: Editora Bookman, 2012. p. 17-46.

SÃO PAULO. Fundação Florestal. Plano de Manejo da APA Itupararanga. Secretaria de Estado de Meio Ambiente, 2010.

SILVA, D. M.; GRANDINE, G.; SIMONETTI, V. C.; SILVA, D. C. C. Análise espacial da cobertura vegetal no centro urbano do município de Salto de Pirapora (SP). Caminhos de Geografia, v. 19, n. 68, p. 361-371, 2018. https://doi.org/10.14393/RCG196824 
SILVA, D. C. C.; ALBUQUERQUE FILHO, J. L.; OLIVEIRA, R. A.; LOURENÇO, R. W. Application of environmental indicators for water analysis in watershed. Revista Brasileira de Geografia Física, v. 10, p. 610-626, 2017b. https://doi.org/10.5935/1984-2295.20170039 SILVA, D. C. C.; FILHO, J. L. A., OLIVEIRA, R. A.; LOURENÇO, R. W. Metodologia para análise do potencial de degradação dos recursos hídricos em bacias hidrográficas. Caderno de Geografia, v. 27, n. 50, p. 455-466, 2017a. http://dx.doi.org/10.5752/p.23182962.2017v27n50p455

SILVA, S. C.; DOVAL, J. C. L. (Org.). Ecologia de reservatórios e interfaces. São Paulo: Instituto de Biociências da Universidade de São Paulo, 2015. p. 212-231.

SILVINO, R. F.; BARBOSA, F. A. R. Eutrophication potential of lakes: an integrated analysis of trophic state, morphometry, land occupation, and land use. Brazilian Journal of Biology, v. 75, n. 3, p. 607-615, 2015. http://dx.doi.org/10.1590/1519-6984.18913

SIMONETTI, V. C.; SILVA, D. C. C.; OLIVEIRA, R. A.; SABONARO, D. Z.; ROSA, A. H. Análise da suscetibilidade do solo a processos erosivos do Parque Natural Municipal Corredores de Biodiversidade (PNMCBIO) de Sorocaba (SP). Raega-O Espaço Geográfico em Análise, v. 44, p. 169-180, 2018. http://dx.doi.org/10.5380/raega.v44i0.48838

STEFANOSKI, D. C.; SANTOS, G. G.; MARCHÃO, R.L.; PETTER, F.A.; PACHECO, L.P. Uso e manejo do solo e seus impactos sobre a qualidade física. Revista Brasileira de Engenharia Agrícola e Ambiental, v. 17, n. 12, 1301-1309, 2013.

TANIWAKI, R. et al. A influência do uso e ocupação do solo na qualidade e genotoxicidade da água no reservatório de Itupararanga, São Paulo, Brasil. Interciência, v. 38, n. 3, p. 164170, 2013. http://www.redalyc.org/comocitar.oa?id=33926977002

TIECHER, T. et al. Contribuição das fontes de sedimentos em uma bacia hidrográfica agrícola sob plantio direto. Revista Brasileira de Ciência do Solo, v. 38, n. 2, p. 639-649, 2013. http://www.redalyc.org/articulo.oa?id=180231134028

TIMM, N. H. Applied multivariate analysis. Nova York: Springer, 2002. 693 p.

VON SPERLING, M. Introdução à qualidade das águas e ao tratamento de esgotos. 3. ed. Belo Horizonte: Departamento de Engenharia Sanitária e Ambiental; Editora: UFMG, 2005.

WETZEL, R. G.; LIKENS, G. E. Limnological analyses. 3. ed. New York: Springer Verlage, 2000.

ZOLIN, C. A.; FOLEGATTI, M. V.; MINGOTI, R.; SÁNCHEZ-ROMÁN, R. M.; PAULINO, J.; ORELLANA GONZÁLES, A. M. G. Minimização da erosão em função do tamanho e localização das áreas de floresta no contexto do programa "Conservador das águas". Revista Brasileira de Ciência do Solo, v. 35, n. 6, p. 2157-2166, 2011.

\section{NOTAS DE AUTOR}

\section{CONTRIBUIÇÃO DE AUTORIA}

Vanessa Cezar Simonetti - Concepção. Coleta de dados, Análise de dados, Elaboração do manuscrito, revisão e aprovação da versão final do trabalho

Darllan Collins da Cunha e Silva - Concepção e elaboração do manuscrito, conduzindo a validação dos dados e produção dos mapas temáticos. Participação ativa da discussão dos resultados; Revisão e aprovação da versão final do trabalho.

André Henrique Rosa - Revisão e aprovação da versão final do trabalho.

\section{FINANCIAMENTO}

Agradecemos à Fapesp (Proc. 2018/20326-1), ao Capes PROBRAL (Proc. 99999.008107/2015-07) e ao CNPq (Proc. 2016/08215-4) pelo suporte financeiro para o desenvolvimento desta pesquisa.

\section{LICENCCA DE USO}

Este artigo está licenciado sob a Licença Creative Commons CC-BY. Com essa licença você pode compartilhar, adaptar, criar para qualquer fim, desde que atribua a autoria da obra.

\section{HISTÓRICO}

Recebido em: 31-05-2018

Aprovado em: 07-06-2019 